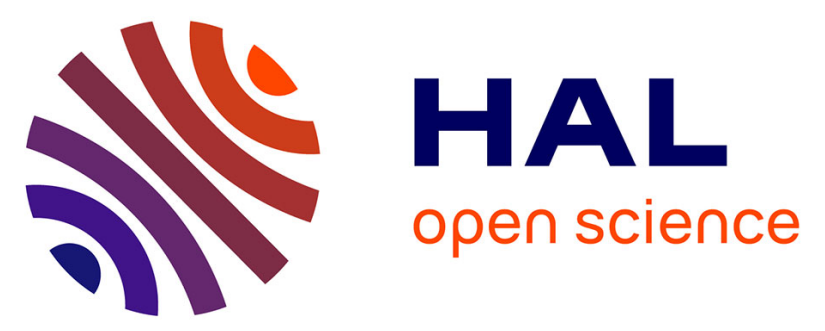

\title{
Non-Heme Fe II Diastereomeric Complexes Bearing a Hexadentate Ligand: Unexpected Consequences for the Spin State and Catalytic Oxidation Properties
}

Katell Sénéchal-david, Charlotte Buron, Nathalie Ségaud, Jean-noël Rebilly, Amandine dos Santos, Jonathan Farjon, Régis Guillot, Christian Herrero, Tanya Inceoglu, Frédéric Banse

\section{To cite this version:}

Katell Sénéchal-david, Charlotte Buron, Nathalie Ségaud, Jean-noël Rebilly, Amandine dos Santos, et al.. Non-Heme Fe II Diastereomeric Complexes Bearing a Hexadentate Ligand: Unexpected Consequences for the Spin State and Catalytic Oxidation Properties. Chemistry - A European Journal, 2019, 25 (53), pp.12405-12411. 10.1002/chem.201902423 . hal-03292399

\section{HAL Id: hal-03292399 \\ https://hal.science/hal-03292399}

Submitted on 26 Jul 2021

HAL is a multi-disciplinary open access archive for the deposit and dissemination of scientific research documents, whether they are published or not. The documents may come from teaching and research institutions in France or abroad, or from public or private research centers.
L'archive ouverte pluridisciplinaire HAL, est destinée au dépôt et à la diffusion de documents scientifiques de niveau recherche, publiés ou non, émanant des établissements d'enseignement et de recherche français ou étrangers, des laboratoires publics ou privés. 


\title{
Non-heme Fe(II) diastereomeric complexes bearing a hexadentate ligand : unexpected consequences on the spin state and oxidation catalytic properties.
}

\author{
Katell Sénéchal-David, ${ }^{\text {[a] }}$ Charlotte Buron, ${ }^{[a]}$ Nathalie Ségaud, ${ }^{[a](b)}$ Jean-Noël Rebilly, ${ }^{[a]}$ Amandine Dos \\ Santos, ${ }^{[a]}$ Jonathan Farjon, ${ }^{[c]}$ Régis Guillot, ${ }^{\left[{ }^{[a]}\right.}$ Christian Herrero, ${ }^{[a]}$ Tanya Inceoglu, ${ }^{[a]}$ and Frédéric \\ Banse $^{*[a]}$
}

\begin{abstract}
The reactivity and selectivity of non-heme Fe" complexes as oxidation catalysts can be substantially modified upon alteration of the ligand backbone or introduction of various substituents. In comparison to the hexadentate ligand TPEN (N,N,N',N'tetrakis(pyridin-2-ylmethyl)ethane-1,2-diamine), $\quad{ }_{2 m e} \mathrm{~L}_{6}{ }^{2} \quad\left(\mathrm{~N}, \mathrm{~N}^{\prime}-\right.$-bis $(1-$ (pyridin-2-yl)ethyl)-N,N'-bis(pyridin-2-ylmethyl)ethane-1,2-diamine) contains one methyl group on two of the four picolyl positions. Fe" complexation by ${ }_{2 \mathrm{Me}} \mathrm{L}_{6}{ }^{2}$ yields two diastereoisomeric complexes with very similar structures, only differing in the axial/equatorial positions occupied by the methylated pyridyl groups. In solution, these two isomers exhibit different magnetic behavior. Whereas one isomer displays a temperature dependent spin state conversion between the $S=0$ and $S=2$ states, the other one is more reluctant for this spin state equilibrium and is essentially diamagnetic at room temperature. Their catalytic properties for anisole oxidation by $\mathrm{H}_{2} \mathrm{O}_{2}$ are very different and correlate with their magnetic properties which reflect their lability / inertness. These different properties most likely rely on the different steric constraints in which the methylated pyridyl groups are engaged in the two complexes.
\end{abstract}

\section{Introduction}

Many mononuclear heme and non heme iron enzymes carry out the oxidation of inert chemical bonds under mild conditions. ${ }^{[1-4]}$ With the aim to develop cheap catalytic systems, numerous non heme iron complexes have been prepared in order to reproduce the function of these enzymes. ${ }^{[5-7]}$ Following the peroxide shunt strategy, some $\mathrm{Fe}^{l l}$ complexes supported by polyazadentate ligands have proven capable of promoting the activation of hydrogen peroxide leading to the oxidation of olefinic or aliphatic substrates ${ }^{[8]}$ as well as the hydroxylation of aromatic $\mathrm{C}-\mathrm{H}$ bonds. ${ }^{\left[{ }^{9}-\right.}$

${ }^{12]}$ Catalytic activities with improved regio- or enantioselectivity

[a] Dr K. Sénéchal-David, Dr C. Buron, Dr N. Ségaud, Dr J.-N Rebilly(s), Mrs A. Dos santos, Dr R. Guillot, Dr. C. Herrero, Mrs T. Inceoglu, Pr. F. Banse

Institut de Chimie Moléculaire et des Matériaux d'Orsay

Univ. Paris-Sud, Univ. Paris-Saclay, CNRS

91405 Orsay cedex, France

E-mail: katell.senechal-david@u-psud.fr, frederic.banse@u-psud.fr

[b] Dr N. Ségaud

Departement für Chemie und Biochemie

Universität Bern

Freiestrasse 3, 3012 Bern, Switzerland

[c] Dr J. Farjon

CEISAM

Université de Nantes, CNRS

2, chemin de la Houssinière, 44322 Nantes cedex 3 , France

Supporting information for this article is given via a link at the end of the document. and efficiency have also been observed with more rigid ligand backbones by replacing the ethylenediamine linker of the ligand by enantiomerically pure bipyrrolidine, ${ }^{[13-16]}$ bipiperidine ${ }^{[17]}$ or cyclohexane diamines. ${ }^{[18]}$ Additionally, the presence of bulky substituents has been shown to strongly influence the site of aliphatic C-H oxidation in different substrates. ${ }^{[19,20]}$ Thus, it appears that any modification on the ligand skeleton can result in important tuning of the catalyst performance. Along this line, we envisioned that methylation of two of the picolyl groups in the TPEN ligand (N,N,N',N'-tetrakis(pyridin-2-ylmethyl)ethane-1,2diamine, Scheme 1) could influence the catalytic properties of $\left[\mathrm{Fe}^{\prime \prime}(\mathrm{TPEN})\right]^{2+}$. The six coordinate $\left[\mathrm{Fe}^{\prime \prime}(\mathrm{TPEN})\right]^{2+}$ displays a spin equilibrium in solution between low spin $(L S, S=0)$ and high spin $(H S, S=2)$ states which is in line with its lability. Thus, it readily reacts with oxidants such as $\mathrm{H}_{2} \mathrm{O}_{2},{ }^{[21]}$ oxygen atom donors ${ }^{[22]}$ and dioxygen ${ }^{[23]}$ yielding reaction intermediates capable of promoting the oxidation of olefins, alkanes ${ }^{[22]}$ and aromatic hydrocarbons. ${ }^{[10,11]}$ Additionally, incorporation of alkyl or aromatic groups at the 2-pyridinylmethyl positions create chiral centers whose location has been demonstrated to be beneficial in asymmetric epoxidation reactions. ${ }^{[24,25]}$
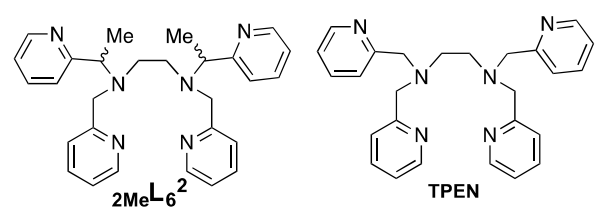

Scheme 1. Ligands used in this study.

In this paper, we report the synthesis, characterization, study of the magnetic behavior in solution and evaluation of the catalytic abilities of two diastereomeric Fe(II) complexes bearing the hexadentate ligand ${ }_{2 \mathrm{Me}} \mathrm{L}_{6}{ }^{2}$ (N,N'-bis(1-(pyridin-2-yl)ethyl)-N,N'bis(pyridin-2-ylmethyl)ethane-1,2-diamine, Scheme 1), in which chiral centers are introduced by methylation of two of the four pyridinylmethyl positions. These two $\left[\mathrm{Fe}^{\prime \prime}\left({ }_{2 \mathrm{Me}} \mathrm{L}_{6}{ }^{2}\right)\right]^{2+}$ complexes (1a and $\mathbf{1 b}$ ) exhibit very similar structures, only differing in the axial/equatorial positions occupied by the methylated pyridyl groups. Unexpectedly, they exhibit distinct catalytic properties towards anisole oxidation by hydrogen peroxide. This can be rationalized by comparing the divergent temperature evolution of their spin state equilibrium in solution, which reflects their relative lability. This characteristic itself can be correlated to the different steric constraints within their coordination sphere. Such drastic consequences arising from very subtle structural changes within twin catalysts have been very rarely documented. ${ }^{[26]}$ 


\section{Results}

The ligand ${ }_{2 \mathrm{Me}} \mathrm{L}_{6}{ }^{2}$ was obtained by a conventional reductive amination route between 3 and pyridine carboxaldehyde in the presence of $\mathrm{NaBH}(\mathrm{OAc})_{3}$, as described in Scheme 2. The diamine 3 was obtained by reduction of the isolated diimine 2 . The detailed experimental procedures are given in Supporting Information.

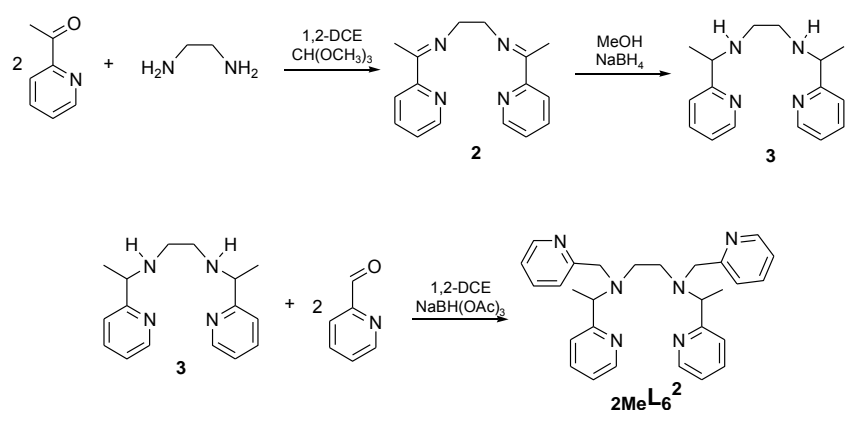

Scheme 2. Synthesis of ligand $2 \mathrm{Me}_{6}{ }^{2}$.

Starting from the diastereomeric mixture of ${ }_{2 \mathrm{Me}} \mathrm{L}_{6}{ }^{2}$, three geometric isomers of $\left[\mathrm{Fe}^{\prime \prime}\left(2 \mathrm{Me}_{6}{ }^{2}\right)\right]^{2+} \mathbf{1}$ can be anticipated, depending on the axial or equatorial position occupied by each of the pyridinylethyl group. Among these three isomers $(\mathbf{1 a}, \mathbf{1 b}$, and $\mathbf{1 c}$, Supplementary Information, Figure S3), only 1a, which displays the two 2-pyridinylethyl groups in the equatorial plane, and $\mathbf{1} \mathbf{b}$, with one 2-pyridinylethyl group in the equatorial plane and the other in axial position, were observed in solution and in the solid state (see NMR study below and Experimental Section). The structures of $\mathbf{1} \mathbf{a} \bullet\left(\mathrm{PF}_{6}\right)_{2}$ and $\mathbf{1} \mathbf{b} \bullet\left(\mathrm{PF}_{6}\right)_{2}$ were determined by single crystal X-ray diffraction at $100 \mathrm{~K}$ (Figure 1). In any isomer of 1. $\left(P F_{6}\right)_{2}$, the ligand wraps the metal center in a hexadentate fashion and all of the Fe-N bond distances are of ca. $2.0 \AA$, indicating a low spin $(\mathrm{S}=0) \mathrm{Fe}^{\prime \prime}$ at $100 \mathrm{~K}$ (Supporting Information, Table S3). Interestingly, isomer $\mathbf{1} \cdot\left(\mathbf{P F}_{6}\right)_{2}$ contains a $S, S / R, R$ racemic mixture of the ligand in the unit cell. To avoid steric congestion between the axial pyridine rings and the methyl groups of the equatorial 2-pyridinylethyl, the $S, S$ ligand is found in the $\Lambda$ complex stereoisomer while the $R, R$ ligand is found in the $\Delta$ complex (Supporting Information, Figure S3). Therefore, the unit cell of $1 \mathbf{1 a} \cdot\left(\mathbf{P F}_{6}\right)_{2}$ only contains the $\Lambda \quad / \Delta$ pair of enantiomers.

In contrast, isomer $\mathbf{1 b} \bullet\left(\mathbf{P F}_{6}\right)_{2}$ (Figure 1 , bottom) contains the meso form $(R, S$ or $S, R)$ of the ligand. For the same steric reasons as in $1 \mathbf{a}$, the number of isomers observed is restrained and the $\Lambda$ complex contains the $S_{\text {equatorial }} R_{\text {axial }}$ ligand while the $\Delta$ complex contains the $R_{\text {equatorial }} S_{\text {axial }}$ ligand. Therefore, the unit cell of $\mathbf{1 b} \cdot\left(\mathrm{PF}_{6}\right)_{2}$ only contains the pair of $\Lambda S_{\text {equatorial }} R_{\text {axial }} / \Delta R_{\text {equatorial }} S_{\text {axial }}$ enantiomers.

At higher temperature ( 293 and $400 \mathrm{~K}$ ), elongation of the $\mathrm{Fe}-\mathrm{N}$ bond distances is observed for both complexes indicative of a low spin $(S=0)$ to high spin state $(S=2)$ equilibrium for both complexes. Nonetheless, the variation in the bond distances is more important for $\mathbf{1 b}\left(\mathbf{P F}_{6}\right)_{2}$ suggesting that the spin state transition occurs at lower temperature for this latter complex (Supporting Information,
Table S3). Magnetic measurements performed on $1 \bullet\left(\mathrm{PF}_{6}\right)_{2}$ shows that this spin state conversion is not complete at $400 \mathrm{~K}$ (Supporting Information, Figure S4).
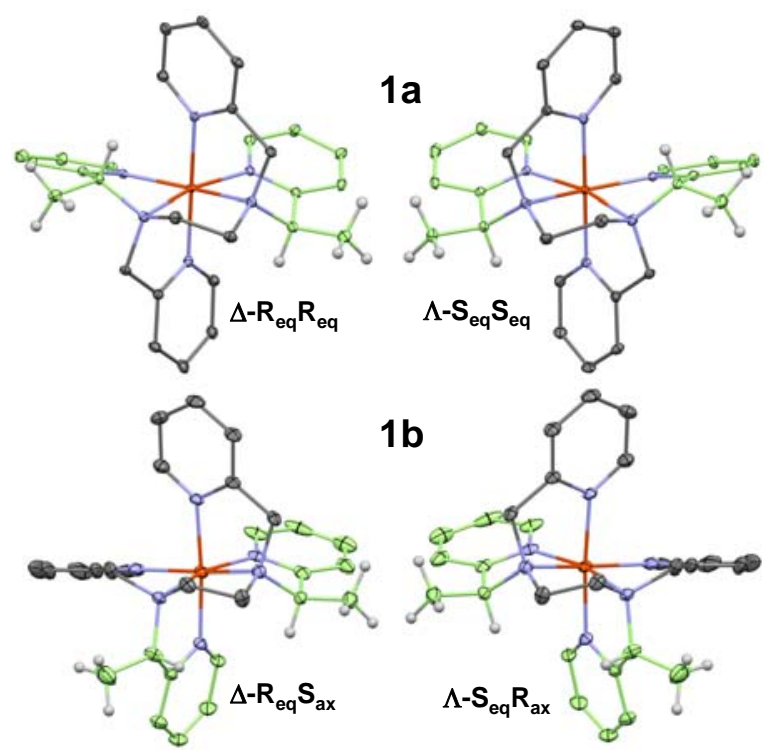

Figure 1. Molecular complexes of the two stereoisomers of $\left[\mathrm{Fe}^{\prime \prime}\left(2 \mathrm{Me} \mathrm{L}_{6}{ }^{2}\right)\right]\left(\mathrm{PF}_{6}\right)_{2}$ 1•(PF $)_{2}$ determined at $100 \mathrm{~K}$ (ellipsoids shown at $50 \%$ ). (Top) The two enantiomers of $1 \mathrm{a}$ with the pyridinylethyl groups occupying two equatorial positions (RR/SS ligand); (Bottom) The two enantiomers of $\mathbf{1 b}$ with the pyridinylethyl groups occupying one equatorial and one axial position (RS/SR ligand). The pyridinylethyl groups are highlighted in green. Only the hydrogen atoms on the stereogenic carbons and the methyl groups are shown.

Despite numerous attempts under different experimental conditions, the two diastereomeric complexes $1 \mathbf{1 a} \cdot\left(\mathbf{P F}_{6}\right)_{2}$ and $\mathbf{1 b}\left(\mathbf{P F}_{6}\right)_{2}$ always crystallized simultaneously as dark red brown crystals in a 1:1 ratio (see NMR studies below, Experimental Section and Supporting Information, Figure S5). Additionally, any attempt to separate the different stereoisomers of the ligand ${ }_{2 \mathrm{Me}} \mathrm{L}_{6}{ }^{2}$ by semi-preparative chiral HPLC or by recrystallization as a salt has been unsuccesful yet. Thus, solution studies were performed using an equimolar mixture of the two isomers in most cases. In some instances, larger crystals of both isomers crystallized and could be manually sorted, yielding samples of $1 \mathbf{1 a}\left(\mathbf{P F}_{6}\right)_{2}$ (pure) and $\mathbf{1 b} \cdot\left(\mathbf{P F}_{6}\right)_{2} \quad(90 \%$ purity) that were used for further characterization (see below). 

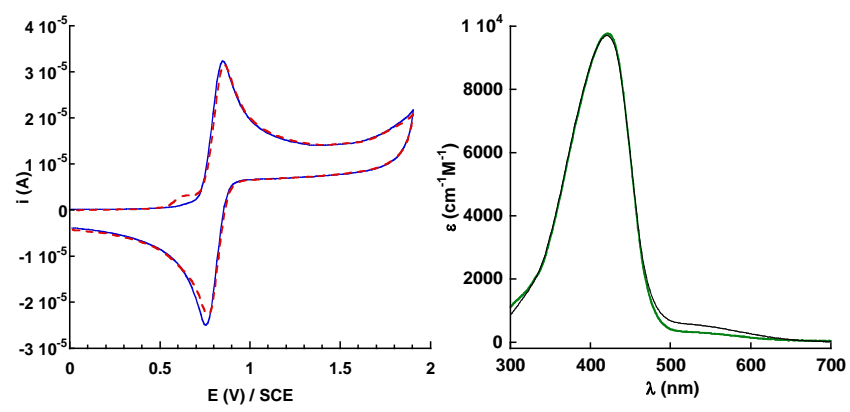

Figure 2. (Left). CV of $\left[\mathrm{Fe}^{\prime \prime}\left(2 \mathrm{Me}_{6}{ }^{2}\right)\right]^{2+} \mathbf{1}$ (blue) and $\left[\mathrm{Fe}^{\prime \prime}(\mathrm{TPEN})\right]^{2+}$ (dashed red) 2

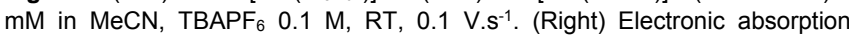
spectrum of $\left[\mathrm{Fe}^{\prime \prime}\left(2 \mathrm{MeL}_{6}{ }^{2}\right)\right]^{2+} \mathbf{1}$ in $\mathrm{MeCN}$ (black line) and in $\mathrm{MeOH}$ (green line).

Cyclic voltammetry (CV) of an acetonitrile solution of the microcrystalline powder of $\mathbf{1} \bullet\left(\mathbf{P F}_{6}\right)_{2}$ (i.e. containing an equimolar mixture of $1 \mathbf{a}$ and $\mathbf{1 b}$ ) displays only one reversible $\mathrm{Fe}^{\mathrm{III} /} / \mathrm{Fe}^{\mathrm{Il}}$ signal at $0.80 \mathrm{~V}$ vs SCE indicating that the two isomers have the same redox properties (Figure 2, left). This signature is also identical to that of $\left[\mathrm{Fe}^{\prime \prime}(\mathrm{TPEN})\right]^{2+}$ (dashed red trace in Figure 2). Additionally, the electronic absorption spectrum of 1 shows a spectral feature independent on the solvent, with a MLCT at $420 \mathrm{~nm}$ and an extinction coefficient of $9700 \mathrm{M}^{-1} \mathrm{~cm}^{-1}$ in both $\mathrm{MeOH}$ and $\mathrm{MeCN}$ (Figure 2, right). All these observations support the conclusion that $1 \mathbf{a}$ and $\mathbf{1 b}$ retain their ligand bound in an hexadentate mode as in $\left[\mathrm{Fe}^{\prime \prime}(\mathrm{TPEN})\right]^{2+}$ upon dissolution in $\mathrm{MeCN}$ or $\mathrm{MeOH}$.

The parent complex [Fe" (TPEN)] ${ }^{2+}$ is known to experience a temperature-dependent spin state conversion in solution between a low spin $(S=0)$ and a high spin state $(S=2) .{ }^{[27]}$ This spin crossover was shown to be connected to a very fast fluxional trigonal distortion. ${ }^{[28]}$ As determined by $\mathrm{X}$-ray crystallography and magnetic susceptibility, $\mathbf{1} \mathbf{a} \bullet\left(\mathbf{P F}_{6}\right)_{2}$ and especially $\mathbf{1} \mathbf{b} \bullet\left(\mathbf{P F}_{6}\right)_{2}$ display a spin state conversion in the solid state. Thus, variable temperature UV-visible absorption analysis of 1 (i.e. containing both $\mathbf{1 a}$ and $\mathbf{1 b}$ ) and [Fe" $(\mathrm{TPEN})]^{2+}$ were performed between 233 and $333 \mathrm{~K}$ and compared to each other (Supplementary Information, Figure S6). For both complexes, the overall decrease of the MLCT band at $420 \mathrm{~nm}$ upon heating is consistent with larger amounts of high spin component. Indeed, the MLCT for high spin $\mathrm{Fe}^{\text {Il }}$ complexes are less intense. ${ }^{[28]}$

The ${ }^{1} \mathrm{H}$ NMR spectrum of 1 in $\mathrm{CD}_{3} \mathrm{CN}$ at room temperature shows both sharp and broad resonances over the $1-14 \mathrm{ppm}$ region (Figure 3 , black trace). The ${ }^{1} \mathrm{H}$ NMR spectrum of $1 \mathrm{a}$ isolated in crystalline form and recorded under the same conditions displays only the set of sharp resonances spanning the diamagnetic region, between 1 and $10 \mathrm{ppm}$ (Figure 3, red trace), and therefore the broad resonances correspond to complex $\mathbf{1 b}$. This indicates that $1 \mathrm{a}$ is essentially diamagnetic and non fluxional (sharp resonances), whereas $\mathbf{1 b}$ which exhibits shifted resonances displays a larger paramagnetic contribution at room temperature.

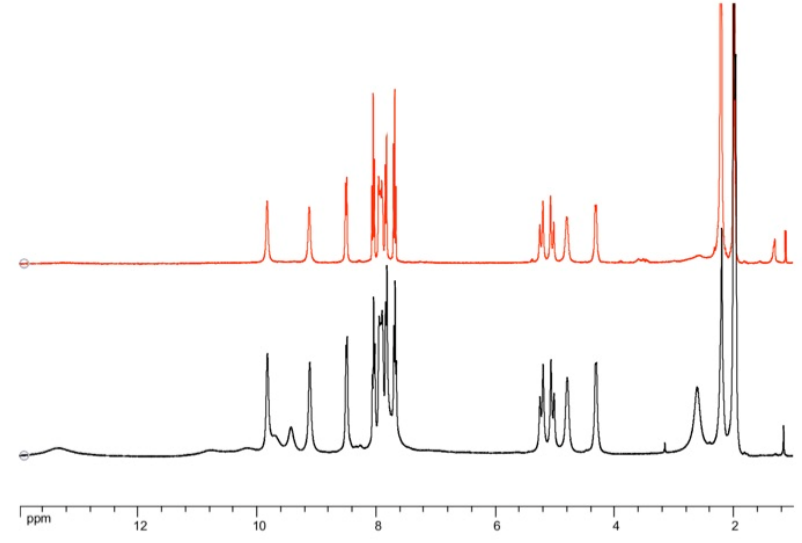

Figure 3. ${ }^{1} \mathrm{H}$ NMR spectrum in $\mathrm{CD}_{3} \mathrm{CN}$ at $293 \mathrm{~K}$ of 1 (black) and of $1 \mathrm{a}$ (red) isolated from the crystalline material of 1 (red)

To substantiate this assertion, variable temperature ${ }^{1} \mathrm{H}$ NMR of 1 and $[\mathrm{Fe} "(\mathrm{TPEN})]^{2+}$ were performed between 233 and 333K.

At $233 \mathrm{~K}, 1$ displays resonances spanning between 1 and $10 \mathrm{ppm}$ (Supplementary Information, Figure S7). This observation indicates that the two isomers $\mathbf{1} \mathbf{a}$ and $\mathbf{1} \mathbf{b}$ are diamagnetic at 233 $\mathrm{K}$. However, one set of signals is sharp, whereas the other is slightly broader and displays much more resonances. Due to its C2 axis, $\mathbf{1 a}$ is expected to display much less resonances than $\mathbf{1 b}$, for which all protons are differentiated (Figure 4 and Supporting Information, Figures S8 and S9 with labeling scheme on Scheme S2). Therefore, the sharp set of resonances can be unambiguously ascribed to 1a while the broader and more numerous peaks correspond to $\mathbf{1 b}$ (complete assignment for $\mathbf{1 a}$, $\mathbf{1 b}$ and $\left[\mathrm{Fe} "(\text { TPEN)}]^{2+}\right.$ in Supporting Information, Figures S13-S19 and S20-22, respectively). Additionally, integration of the spectrum of 1 at $233 \mathrm{~K}$ shows that 1 is constituted of an equimolar mixture of $1 \mathbf{a}$ and $\mathbf{1 b}$ (Figure 4).

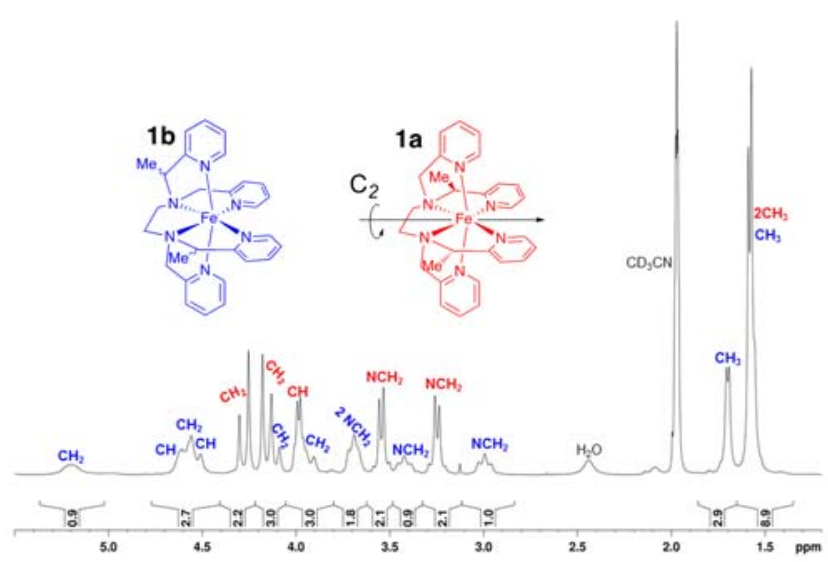

Figure 4. ${ }^{1} \mathrm{H}$ NMR spectrum of 1 in $\mathrm{CD}_{3} \mathrm{CN}$ at $233 \mathrm{~K}$ showing the resonances of aliphatic protons of $\mathbf{1 a}$ (red) and $\mathbf{1 b}$ (blue). The resonances are labeled according to Supplementary information, Scheme S2. 
Increasing the temperature up to $333 \mathrm{~K}$ results in a progressive shift of all of the resonances indicating the emergence of a spin crossover phenomenon between low spin $(S=0)$ and high spin $(\mathrm{S}=2) \mathrm{Fe}$ ll for both $\mathbf{1 a}$ and $\mathbf{1 b}$ (Supplementary Information, Figures S10-S12). Nonetheless, while the resonances of 1a remain essentially sharp (fwhm ca. 20-30 Hz) and moderately shifted, those related to $\mathbf{1 b}$ are significantly broadened (fwhm ca. 30-100 $\mathrm{Hz}$ ) and experience larger displacements.
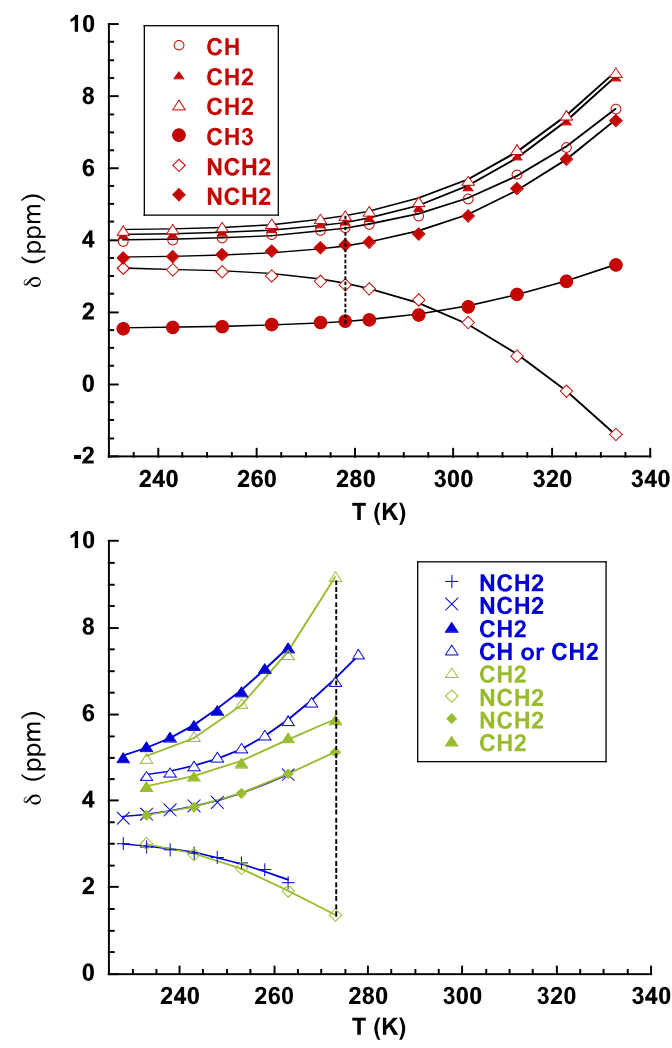

Figure 5. Temperature dependence of the chemical shifts in $\mathrm{CD}_{3} \mathrm{CN}$ for several aliphatic protons of $\mathbf{1 a}$ (red) and $\mathbf{1 b}$ (blue) and $\left[\mathrm{Fe}\left(\mathrm{TPEN}^{\mathrm{b}}\right)\right]\left(\mathrm{PF}_{6}\right)_{2}$ (green). The solid lines are fits to the data (see text for details). The vertical dashed line compares the spectral range for the different complexes at $273 \mathrm{~K}$. The resonances are labeled as indicated in Supplementary information, Scheme S2.

Figure 5 (top, red symbols) displays the chemical shift variation for the aliphatic protons of $1 \mathrm{a}$ between 233 and $333 \mathrm{~K}$. Only very slight changes are observed up to $273 \mathrm{~K}$ from which temperature the chemical shifts start to deviate. For $\mathbf{1 b}$ and $\left[\mathrm{Fe} \mathrm{e}^{\prime \prime}(\mathrm{TPEN})\right]^{2+}$, the severe line broadening and shift readily starts from $233 \mathrm{~K}$ and increases quickly, preventing to track the resonances beyond 270 $\mathrm{K}$ (Figure 5, bottom, blue and green symbols for $\mathbf{1 b}$ and $\left[\mathrm{Fe}^{\prime \prime}(\mathrm{TPEN})\right]^{2+}$, respectively, Supplementary information, Figures S10-S12). This indicates a comparable magnetic behavior in solution for $\mathbf{1 b}$ and [Fe"(TPEN)] $]^{2+}$. Consequently, at $273 \mathrm{~K}$, the spectral range observed for $\mathbf{1 b}$ is significantly larger than that of 1a (see dashed vertical lines in Figure 5). For this latter complex, higher temperatures must be reached to observe a significant shift of its resonances (Supporting Information, Figure S11).
Accordingly, the deviation from Curie behaviour, which reflects the spin crossover phenomenon, is observed at higher temperatures for $\mathbf{1 a}$ than for $\mathbf{1 b}$ and $\left[\mathrm{Fe} \mathrm{e}^{\|}(\mathrm{TPEN})\right]^{2+}$ (Supporting Information, Figure S23). These observations support that the low spin to high spin conversion is more difficult for $\mathbf{1 a}$ and are in line with the observations in the solid state. As reported by Weber and Walker, ${ }^{[29]}$ the chemical shifts of protons are suitable tools for following a spin transition in solution. Modeling the ${ }^{1} \mathrm{H}$ NMR data to equation 1 allows to extract the thermodynamic parameters of the Boltzmann equilibrium between the high spin and low spin states, where $\delta$ is the measured chemical shift, $\delta_{l s}$ the corresponding shift in the diamagnetic state, and $C$ the appropriate Curie's law constant.

$$
\delta=\delta_{l s}+\frac{C}{T\left[1+\exp \left(\frac{\Delta H}{R}\left(\frac{1}{T}-\frac{1}{T_{1}}\right)\right)\right]}
$$

This method has proven useful to model the spin crossover properties of complexes in solution. ${ }^{[30,31]}$ The fits are shown as solid lines in Figure 5 for $\mathbf{1 a}$ and $\mathbf{1 b}$ and the values extracted from these fits are given in Table 1.

Hence, at room temperature, there is a larger fraction of the high spin configuration for $\mathbf{1 b}$ and $\left[\mathrm{Fe} \mathrm{e}^{\prime \prime}(\mathrm{TPEN})\right]^{2+}$ than for $\mathbf{1 a}$. Indeed, 1a remains essentially low spin at $293 \mathrm{~K}$ whereas $\mathbf{1 b}$ and $\left[\mathrm{Fe}^{\prime \prime}(\mathrm{TPEN})\right]^{2+}$ exhibit a predominant high spin configuration (Table 1).

Table 1. Estimates of the thermodynamic parameters of the spin equilibria in $\mathbf{1 a} \bullet\left(\mathrm{PF}_{6}\right)_{2}$ and $\mathbf{1 b} \bullet\left(\mathrm{PF}_{6}\right)_{2}$ in MeCN solution.

\begin{tabular}{lllll}
\hline Complex & $\Delta \mathrm{H}\left(\mathrm{kJ} . \mathrm{mol}^{-1}\right)$ & $\Delta \mathrm{S}\left(\mathrm{J} . \mathrm{K}^{-1} \cdot \mathrm{mol}^{-1}\right)$ & $\mathrm{T}_{1 / 2}$ & $\gamma_{\mathrm{HS}}$ at $293 \mathrm{~K}$ \\
\hline $\mathbf{1 a}$ & 40.1 & 111 & 361 & $4 \%$ \\
$\mathbf{1 b}$ & 36.8 & 134 & 274 & $73 \%$ \\
{$\left[\mathrm{Fe}^{\prime \prime}(\mathrm{TPEN})\right]^{2+}$} & 39.9 & 142 & 281 & $67 \%$ \\
\hline
\end{tabular}

The catalytic efficiency of [Fe" (TPEN) ${ }^{2+}$ and related complexes for the hydroxylation of aromatic substrates by $\mathrm{H}_{2} \mathrm{O}_{2}$ has been previously reported. ${ }^{10,11]}$ Therefore, we have evaluated the catalytic properties of $\left[\mathrm{Fe}^{\prime \prime}\left(2 \mathrm{Me}_{6} \mathrm{~L}_{6}\right)\right]^{2+} \mathbf{1}$ in the oxidation of anisole by $\mathrm{H}_{2} \mathrm{O}_{2}$ and compared them to those of the reference complex $\left[\mathrm{Fe}^{\prime \prime}(\mathrm{TPEN})\right]^{2+}$ (Table 2). The oxidation of the phenol products is much easier than the initial oxygenation of anisole leading to mixtures that can be difficult to analyze. ${ }^{9}$ Thus, the catalytic assays were performed using a large excess of substrate to prevent over-oxidation of the phenol products. ${ }^{[10,11,32]}$ Thereby, restricting the catalytic reaction of the substrate to its 2-electrons oxidation allows comparing the efficacy of different catalysts.

At $293 \mathrm{~K}, \mathbf{1}$ (containing an equimolar mixture of $\mathbf{1 a}$ and $\mathbf{1 b}$, see Figure 4 ) leads to an overall ca. $50 \%$ conversion of the oxidant into the different phenol products (Table 2). Interestingly, the reaction also displays a good chemoselectivity for aromatic hydroxylation (leading to methoxyphenols) vs oxidative demethylation (yielding phenol). Additionally, reactivity occurs on the electron enriched ortho- and para- positions with a regioselectivity in favor of the ortho-methoxyphenol well above 
the statistic value of 2. As seen in Table 2, these results are almost identical to those observed with $\left[\mathrm{Fe}^{\prime \prime}(\mathrm{TPEN})\right]^{2+}$. Oxidation of aromatic substrates by Fenton reagents have been shown to give rise to more diverse products mixtures. ${ }^{[33]}$ Here, the use of $\mathrm{Fe}(\mathrm{OTf})_{2}$ instead of a complex under otherwise identical conditions did not lead to the formation of methoxyphenols. Such an ability to promote the oxidation of aromatic molecules with these significant regio- and chemoselectivities have been

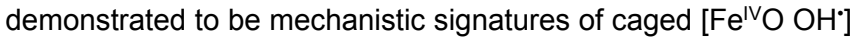
active species generated from LS $\left(\mathrm{N}_{5}\right) \mathrm{Fe}^{\prime \prime \prime}(\mathrm{OOH})$ intermediates..$^{[9,34,35]}$ Thus, this conclusion most probably applies to 1 as well. Note that EPR detection of LS Fe"II $(\mathrm{OOH})$ generated from 1 also supports this hypothesis (Supplementary Information, Figure S24).

Interestingly, catalytic assays using a batch of 1 a complex isolated from the crystalline material of 1 lead to similar regio- and chemoselectivities to those observed with 1 but with much lower conversions suggesting that $\mathbf{1 b}$ is much more reactive than $\mathbf{1 a}$. This is confirmed by catalytic runs using a sample enriched in $\mathbf{1 b}$ (i.e. 1b/1a 9/1) which displays almost the same activity as 1 (Table 2). This suggests that during the catalytic run with sample $\mathbf{1}(\mathbf{1} \mathbf{b} / \mathbf{1} \mathbf{a} 1 / 1$ mixture), $\mathbf{1 b}$ is responsible for the nearly whole catalytic activity observed.

$-$

Table 2. Oxidation of anisole by $\mathrm{H}_{2} \mathrm{O}_{2}$ catalyzed by $[\mathrm{Fe} \text { "IPEN) }]^{2+}, \mathbf{1}, \mathbf{1 a}$, and 1b. Catalytic activity reported as yields $\%$ vs $\mathrm{H}_{2} \mathrm{O}_{2}$ and TON (TON).

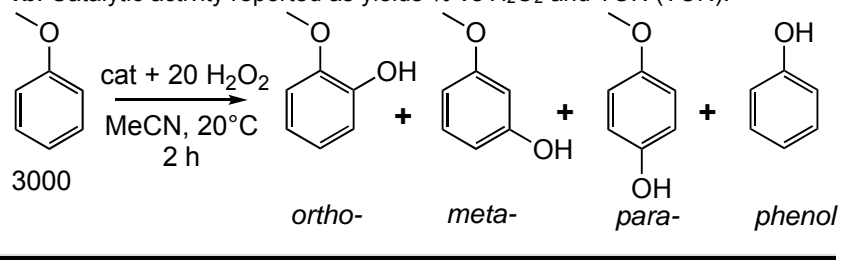

\begin{tabular}{|c|c|c|c|c|}
\hline & ${ }_{+}^{\left[F^{\| \prime}(T P E N)\right]^{2}}$ & $1^{[\mathrm{b}]}$ & $1 \mathrm{a}^{[\mathrm{c}]}$ & $1 b^{[d]}$ \\
\hline ortho- & $37 \%(7.4)$ & $35 \%(7.0)$ & $13 \%(2.6)$ & $\begin{array}{l}34 \% \\
(7.6)\end{array}$ \\
\hline para- & $5 \%(1.0)$ & $7 \%(1.4)$ & $2 \%(0.4)$ & $3 \%(0.7)$ \\
\hline meta- & $1 \%(0.2)$ & $1 \%(0.2)$ & - & - \\
\hline phenol & $6 \%(1.2)$ & $8 \%(1.6)$ & $4 \%(0.8)$ & $5 \%(1.1)$ \\
\hline total & $49 \%(9.6)$ & $51 \%(10.2)$ & $19 \%(3.9)$ & $\begin{array}{l}42 \% \\
(9.3)\end{array}$ \\
\hline regioselectivity[e] & 7.4 & 5 & 6.5 & 11 \\
\hline $\begin{array}{l}\text { chemoselectivity[ } \\
\text { f] }\end{array}$ & 7.2 & 5.4 & 3.7 & 7.4 \\
\hline
\end{tabular}

[a] Yields and TON determined by GC after extraction of the reaction mixture in $\mathrm{Et}_{2} \mathrm{O}$. Values are the average of at least three reactions. [b] Microcrystalline powder of $\mathbf{1} \bullet\left(\mathbf{P F}_{6}\right)_{2}$ containing $\mathbf{1}_{\mathbf{a}} \bullet\left(\mathrm{PF}_{6}\right)_{2}$ and $\mathbf{1} \mathbf{b} \bullet\left(\mathrm{PF}_{6}\right)_{2}$ (equimolar mixture). [c] Single crystals of $1 \mathbf{a} \bullet\left(P_{6}\right)_{2}$ manually sorted. [d] $\mathbf{1 b} \bullet\left(\mathbf{P F}_{6}\right)_{2} / \mathbf{1 a} \bullet\left(\mathbf{P F}_{6}\right)_{2}$ 9/1. TONs corrected for the $90 \%$ purity in $\mathbf{1 b} \bullet\left(\mathbf{P F}_{6}\right)_{2}$. [e] ortho-/para-. [f] (ortho- + para- + meta-)/phenol.

\section{Discussion}

1a and $\mathbf{1 b}$ exhibit the same coordination sphere and display thermodynamic properties (redox potential) close to those of $\left[\mathrm{Fe}^{\prime \prime}(\mathrm{TPEN})\right]^{2+}$ (Figure 2). Along this line, the reaction intermediate responsible for the oxidation of anisole generated from either $\mathbf{1 a}$ and $\mathbf{1 b}$ must have the same reactivity and, therefore, should lead to a similar catalytic activity. However, while the catalytic behaviour of $\mathbf{1 b}$ is in line with that of $\left[\mathrm{Fe}^{\prime \prime}(\mathrm{TPEN})\right]^{2+}, \mathbf{1 a}$ is much less active (Table 2). This distinct behaviour between $\mathbf{1 a}$ and $\mathbf{1 b}$ can thus only be rationalized by kinetic arguments. As determined by NMR, $\mathbf{1 b}$ displays a significant $\mathrm{HS}$ fraction at room temperature, and is thus labile, whereas $1 \mathrm{a}$ is mainly diamagnetic and much more inert. Hence, it can be proposed that $\mathbf{1 b}$ reacts faster than 1a with $\mathrm{H}_{2} \mathrm{O}_{2}$ to form the reaction intermediates involved in the hydroxylation of anisole. The 3 steps to yield the reactive species are :[36]

(i) $\mathrm{Fe}^{\prime \prime}+\mathrm{H}_{2} \mathrm{O}_{2} \leftrightarrows \mathrm{Fe}^{\text {III }}(\mathrm{OH})+\mathrm{HO}$.

(ii) $\mathrm{Fe}^{\text {III }}(\mathrm{OH})+\mathrm{H}_{2} \mathrm{O}_{2} \leftrightarrows \mathrm{Fe}^{\text {III }}(\mathrm{OOH})+\mathrm{H}_{2} \mathrm{O}$

(iii) $\mathrm{Fe}^{\text {III }}(\mathrm{OOH}) \leftrightarrows \mathrm{Fe}^{\mathrm{IV}} \mathrm{O}+\mathrm{HO}$ •

With most non-heme Fe ${ }^{\text {Il }}$ complexes, ${ }^{[36-39]}$ including $\left[\mathrm{Fe}^{\text {II }}(\mathrm{TPEN})\right]^{2+}$, the rate determining step (rds) is step (iii), and the faster step (i), allowing the accumulation of the $\mathrm{Fe}^{\mathrm{II}}(\mathrm{OOH})$ intermediate. With 1, the $\mathrm{Fe}^{\text {III }}(\mathrm{OOH})$ intermediates can be observed by EPR (Supporting Information, Figure S24) but they do not accumulate enough to be observed by UV-visible suggesting step (iii) is most probably not the rds for $\mathbf{1}$. Nonetheless, the rate constant for step (i) can be extracted by UV-visible monitoring of the oxidation of $\mathbf{1}$ by $\mathrm{H}_{2} \mathrm{O}_{2}$. Interestingly, the decay of its $420 \mathrm{~nm} \mathrm{MLCT} \mathrm{is}$ constituted of two first order kinetic regimes (Supplementary Information, Figure S25). One of these phases is fast and attributed to $\mathbf{1 b}$, whereas the other is much slower and attributed to the reaction of $1 \mathrm{a}$ with $\mathrm{H}_{2} \mathrm{O}_{2}$.
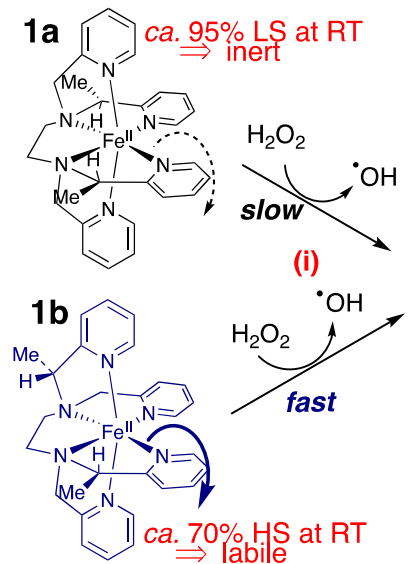

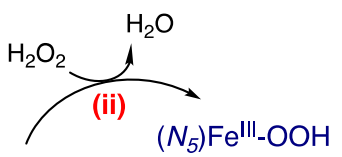

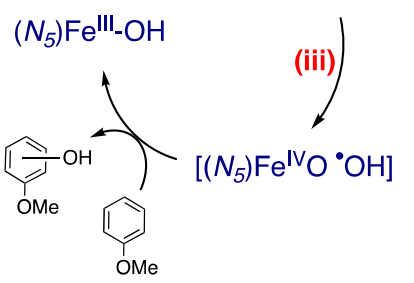

Scheme 3. Proposed mechanism to account for the different catalytic activity of $\mathbf{1 a}$ and $\mathbf{1 b}$ based on their different lability (the catalytic cycle is adapted from ref. 9). 
The mechanism of aromatic hydroxylation by nonheme $\mathrm{Fe}^{\mathrm{Il}} / \mathrm{H}_{2} \mathrm{O}_{2}$ systems has been previously elucidated ${ }^{[9,34,35]}$ and serves as basis to account for the different reactivity of $\mathbf{1 a}$ and $\mathbf{1 b}$ (Scheme 3). Both $\mathbf{1 a}$ and $\mathbf{1 b}$ react with $\mathrm{H}_{2} \mathrm{O}_{2}$ following two parallel inner sphere oxidation to form $\mathrm{Fe}^{\text {"II }}(\mathrm{OH})$ species (step (i)) but at very different rates (Figure S25). Being more reactive by more than one order of magnitude, $\mathbf{1} \mathbf{b}$ enters much more rapidly in the catalytic cycle to form the $\mathrm{Fe}^{\prime \prime \prime}(\mathrm{OOH})$ intermediate and the resulting $\left[\mathrm{Fe}^{\mathrm{IV}} \mathrm{O}{ }^{\circ} \mathrm{OH}\right]$. Whatever the $\mathbf{1 a} / \mathbf{1 b}$ ratio, $1 / 1$ or $1 / 9$, present in the mixture, complex $\mathbf{1 b}$ is responsible for most of the $\mathrm{H}_{2} \mathrm{O}_{2}$ consumption and oxidation of the substrate. Along this line, the same conversions must be obtained starting from either of these samples, in agreement with the experimental results reported in Table 2.
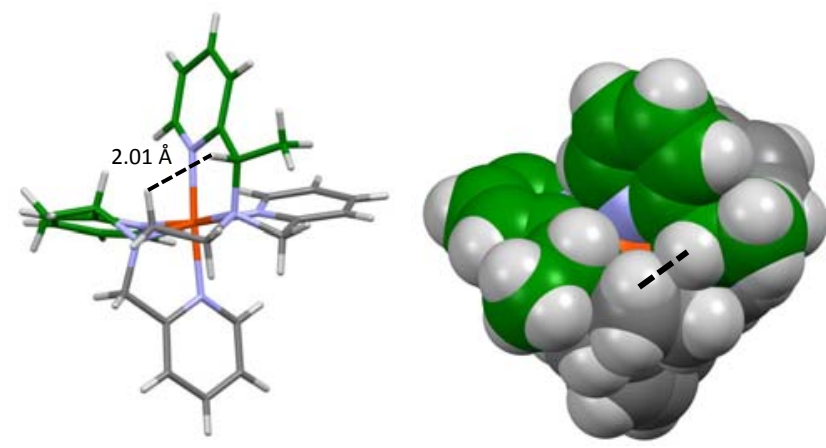

Figure 6. Stick diagram and space filling view of $\mathbf{1 b}$ showing the close contacts present between $\mathrm{H}$ atoms.

Looking into more details into the molecular structures of 1a and $\mathbf{1 b}$ may provide insights into this reactivity difference. In $\mathbf{1 b}$, the distance between the $\mathrm{H}$ atom of the axial pyridinylethyl and the $\mathrm{H}$ atom of a neighbouring $\mathrm{CH}_{2}$ group of the equatorial ethylenediamine fragment is extremely short (Figure 6 and Figure S26). Such very short contacts, way beyond the sum of Van der Waals radii $(2.4 \AA)^{[40]}$ are absent from the structure of $1 \mathrm{a}$ (Supplementary Information, Figure S26). They suggest a significant steric congestion in $\mathbf{1 b}$, unlike $\mathbf{1 a}$.

Relaxation of the steric clash in $\mathbf{1 b}$ can be achieved by lengthening of the Fe-ligand bonds, thus weakening the ligand field and favoring the low spin to high spin state conversion, in concordance with our observations.

Conversely, 1a does not display such a steric congestion in the solid state and, compared to $\mathbf{1 b}$, does not exhibit a large paramagnetic contribution at room temperature.

The relaxation of steric congestion thus appears as a possible driving force for the low spin to high spin state conversion and, hence, for the faster formation of $\mathrm{Fe}^{\prime \prime \prime}(\mathrm{OOH}$ ) (and the subsequent anisole oxidation) with $\mathbf{1 b}$ than with $\mathbf{1 a}$

\section{Conclusions}

Ferrous complexes prepared from the hexadentate ${ }_{2 \mathrm{Me}} \mathrm{L}_{6}{ }^{2}$ ligand exist as two diastereomeric complexes, $\mathbf{1 a}$ and $\mathbf{1 b}$, structurally characterized at the solid state as their $\mathrm{PF}_{6}{ }^{-}$salts. In the solid state, these complexes exhibit very similar bond distances and angles but differ in the axial or equatorial coordination positions occupied by the 2-pyridinylethyl or 2-pyridinylmethyl groups. Such apparently subtle changes lead to a different steric congestion in the two complexes, which is probably a source for their distinct magnetic behaviour in solution. Indeed, $\mathbf{1 a}$ is essentially diamagnetic (low spin $\mathrm{Fe}^{\text {"l) }}$ ) from low to room temperature whereas 1b undergoes a conversion between diamagnetic and paramagnetic states (high spin $\mathrm{Fe}^{\| l} \mathrm{~S}=2$ ). Furthermore, these slight structural changes also affect reactivity: $\mathbf{1 b}$ is a better catalyst in the oxidation of anisole by $\mathrm{H}_{2} \mathrm{O}_{2}$ than 1 a. This can be assigned to the increased lability of $\mathbf{1} \mathbf{b}$. Thus, $\mathbf{1} \mathbf{b}$ reacts fastly with $\mathrm{H}_{2} \mathrm{O}_{2}$ whereas $1 \mathrm{a}$ is sluggish. The relationships between structural properties, spin states and reactivity of coordination complexes is often evoked but there are rather few reported experimental data to support the claims. Our present study provides clear experimental evidences in that direction.

Future work in our lab is aimed at incorporating two $\mathrm{CH}_{3}$ groups at the picolyl positions instead of one to create a steric congestion whose relaxation would favor the stabilization of the high spin state, which is beneficial for an efficient catalytic activity.

\section{Experimental Section}

Synthesis of $\left[\mathrm{Fe}\left({ }_{2 \mathrm{Me}} \mathrm{L}_{6}{ }^{2}\right)\right]\left(\mathrm{PF}_{6}\right)_{2} \mathbf{1} \cdot\left(\mathrm{PF}_{6}\right)_{2}$. In a glovebox, $\mathrm{Fe}(\mathrm{OTf})_{2}(1.70 \mathrm{~g}$, $4.8 \mathrm{mmol}$ ) dissolved in a minimum volume of $\mathrm{MeOH}$ was added dropwise

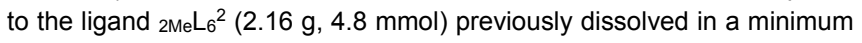
volume of $\mathrm{MeOH}$. The resulting orange-brown solution was allowed to stir for 30 minutes, then 2.2 equiv. $\mathrm{NaPF}_{6}(1.59 \mathrm{~g}, 10.7 \mathrm{mmol})$ dissolved in a minimum of $\mathrm{MeOH}$ was added dropwise. A red-brown solid precipitated and the reaction mixture was allowed to stir for one night. The solid was collected by filtration, washed with $\mathrm{Et}_{2} \mathrm{O}$ and dried under vacuum to yield $\left[\mathrm{Fe}\left({ }_{2 \mathrm{MeL}}{ }^{2}\right)\right]\left(\mathrm{PF}_{6}\right)_{2} \mathbf{1} \mathbf{1}\left(\mathrm{PF}_{6}\right)_{2}$ as an orange-brown powder with a yield of $68 \%$. Elemental Analysis (\%) found C 41,5, H 4.0, N 10.2; expected C 42.1, $\mathrm{H} 4,0, \mathrm{~N} 10.5$. This indicates that the microcrystalline powder is solvent free, in agreement with the crystal structures of $1 \mathbf{1 a}\left(\mathbf{P F}_{6}\right)_{2}$ and 1b•(PF6)2. HR-ESI-MS ( $\left.\mathrm{CH}_{3} \mathrm{CN}\right): \mathrm{m} / \mathrm{z} 254.1036$ (calcd. 254.1013 for $\left.\left[\mathrm{Fe}\left(2 \mathrm{MeL}_{6}{ }^{2}\right)\right]^{2+}\right)$. UV-visible : $(\mathrm{MeOH}) \lambda_{\max }(\mathrm{nm})\left[\varepsilon\left(\mathrm{M}^{-1} \cdot \mathrm{cm}^{-1}\right)\right]: 420(8600)$, 250 (>25 000); $\left(\mathrm{CH}_{3} \mathrm{CN}\right) \lambda_{\max }(\mathrm{nm})\left[\varepsilon\left(\mathrm{M}^{-1} . \mathrm{cm}^{-1}\right)\right]: 420$ (9000), 250 (14000). Single crystals were obtained by slow diffusion of tert-butyl ethylether in a $\mathrm{CH}_{3} \mathrm{CN}$ solution of the complex. $\mathbf{1} \mathbf{a} \bullet\left(\mathbf{P F}_{6}\right)_{2}$ and $\mathbf{1} \mathbf{b} \bullet\left(\mathbf{P F}_{6}\right)_{2}$ always crystallized simultaneously as dark red brown crystals which complicated their isolation. In some instances, larger crystals of both isomers crystallized and could be manually sorted, taking advantadge of their different shape. $\mathbf{1} \mathbf{1} \bullet\left(\mathbf{P F}_{6}\right)_{2}$ appear as plates whereas $\mathbf{1} \mathbf{b} \bullet\left(\mathbf{P F}_{6}\right)_{2}$ are needleshaped crystals (Supporting Information, Figure S5). As shown by NMR (see Figure 4 in the main text and NMR section in the Supporting Information), any crop of solid $1 \bullet\left(\mathbf{P F}_{6}\right)_{2}$ contained an equimolar mixture of isomers $\mathbf{1 a} \bullet\left(\mathrm{PF}_{6}\right)_{2}$ and $\mathbf{1} \mathbf{b} \bullet\left(\mathrm{PF}_{6}\right)_{2}$.

Catalytic assays were carried out with the following samples composition : catalyst $(1 \mathrm{mM}) / \mathrm{H}_{2} \mathrm{O}_{2}$ /anisole $1 / 20 / 3000$ in $\mathrm{MeCN}$ for $2 \mathrm{~h}$ at $20^{\circ} \mathrm{C}$. The products were analyzed and quantified by GC with respect to commercial standards after extraction of the reaction mixture in $\mathrm{Et}_{2} \mathrm{O}$. The results given are the mean of 3 experiments. Blank experiments with $\mathrm{Fe}^{\prime \prime}(\mathrm{OTf})_{2}$ instead of the catalyst did not yield any oxidation product. 


\section{Acknowledgements}

Eric Rivière and Jean-Pierre Baltaze are acknowledged for their precious help. This work is supported by a public grant overseen by the French National Research Agency (ANR) as part of the "Investissements d'Avenir" program (Labex charmmmat, reference: ANR-11-LABX-0039-grant). The ECOSTBio Action CM1305 is also acknowledged for support

Keywords: iron $\cdot \mathrm{N}$ ligands $\cdot$ spin states $\cdot \mathrm{NMR} \cdot$ catalysis

[1] I. Gamba, Z. Codolà, J. Lloret-Fillol, M. Costas, Coord. Chem. Rev. 2016, 1-23.

[2] P. R. Ortiz de Montellano, Chem. Rev. 2010, 110, 932-948.

[3] C. Krebs, D. Galonić Fujimori, C. T. Walsh, J. M. Bollinger, Acc. Chem. Res. 2007, 40, 484-492. Chem. Res. 2007, 40, 484-492.
S. M. Barry, G. L. Challis, ACS Catal. 2013, 3, 2362-2370.

[4] S. M. Barry, G. L. Challis, ACS Catal. 2013, 3, 2362-2370. $1146-1154$.

[6] P. C. A. Bruijnincx, G. van Koten, R. J. M. Klein Gebbink, Chem. Soc. Rev. 2008, 37, 2716.

[7] X. Engelmann, I. Monte-Pérez, K. Ray, Angew. Chem. Int. Ed. 2016, 55, 7632-7649.

[8] G. Olivo, O. Cussó, M. Borrell, M. Costas, J Biol Inorg Chem 2017, 22, 425-452.

[9] A. Thibon, V. Jollet, C. Ribal, K. Sénéchal-David, L. Billon, A. B. Sorokin, F. Banse, Chem. Eur. J. 2012, 18, 2715-2724

[10] A. Thibon, J.-F. Bartoli, R. Guillot, J. Sainton, M. Martinho, D. Mansuy, F. Banse, J. Mol. Catal. A 2008, 287, 115-120.

[11] V. Balland, D. Mathieu, N. Pons-Y-Moll, J.-F. Bartoli, F. Banse, P. Battioni, J.-J. Girerd, D. Mansuy, J. Mol. Catal. A 2004, 215, 8187.

[13] M. S. Chen, M. C. White, Science 2007, 318, 783-787.

[14] P. Spannring, V. Yazerski, P. C. A. Bruijnincx, B. M.

Weckhuysen, R. J. M. Klein Gebbink, Chem. Eur. J. 2013, 19

15012-15018.

[15] O. Cussó, I. Garcia-Bosch, X. Ribas, J. Lloret-Fillol, M. Costas, J. Am. Chem. Soc. 2013, 135, 14871-14878.

[16] M. Mitra, O. Cussó, S. S. Bhat, M. Sun, M. Cianfanelli, M. Costas, E. Nordlander, Dalton Trans. 2019, 48, 6123-6131.

[17] E. A. Mikhalyova, O. V. Makhlynets, T. D. Palluccio, A. S. Filatov, E. V. Rybak-Akimova, Chem. Commun. 2012, 48, 687-689. M. Costas, A. K. Tipton, K. Chen, D.-H. Jo, L. Que, J. Am. Chem.

[19] Soc. 2001, 123, 6722-6723. P. E. Gormisky,

[20] D. Font, M. Canta, M. Milan, O. Cussó, X. Ribas, R. J. M. Klein Gebbink, M. Costas, Angew. Chem. Intl. Ed. 2016, 128, 58705873 .

[21] A. J. Simaan, S. Döpner, F. Banse, S. Bourcier, G. Bouchoux, A. Boussac, P. Hildebrandt, J.-J. Girerd, Eur. J. Inorg. Chem. 2000, 2000, 1627-1633.

[22] M. Martinho, F. Banse, J.-F. Bartoli, T. A. Mattioli, P. Battioni, O. Horner, S. Bourcier, J.-J. Girerd, Inorg. Chem. 2005, 44, 95929596.

[23] N. Ségaud, E. Anxolabéhère-Mallart, K. Sénéchal-David, L. Acosta-Rueda, M. Robert, F. Banse, Chem. Sci. 2015, 6, 639647.

M. Wu, Bin Wang, S. Wang, C. Xia, W. Sun, Org. Lett. 2009, 11, 3622-3625.

M. Wu, C.-X. Miao, S. Wang, X. Hu, C. Xia, F. E. Kühn, W. Sun, Adv. Synth. Catal. 2011, 353, 3014-3022.

[26] M. Grau, A. Kyriacou, F. C. Martinez, I. M. de Wispelaere, A. J. P White, G. J. P. Britovsek, Dalton Trans. 2014, 43, 17108-17119. H. Toftlund, Monatshefte Fur Chemie 2001, 132, 1269-1277. H. R. Chang, J. K. McCusker, H. Toftlund, S. R. Wilson, A. X. Trautwein, H. Winkler, D. N. Hendrickson, J. Am. Chem. Soc. 1990, 112, 6814-6827.

[28]
D. Mathieu, J.-F. Bartoli, P. Battioni, D. Mansuy, Tetrahedron 2004, 60, 3855-3862.

C. Walling, R. A. Johnson, J. Am. Chem. Soc. 1975, 97, 363367.

A. S. Faponle, M. G. Quesne, C. V. Sastri, F. Banse, S. P. de Visser, Chem. Eur. J. 2015, 21, 1221-1236.

A. S. Faponle, F. Banse, S. P. de Visser, J Biol Inorg Chem 2016 21, 453-462.

J. Chen, A. Draksharapu, D. Angelone, D. Unjaroen, S. K. Padamati, R. Hage, M. Swart, C. Duboc, W. R. Browne, ACS Catal. 2018, 8, 9665-9674.

G. Roelfes, M. Lubben, K. Chen, R. Y. N. Ho, A. Meetsma, S. Genseberger, R. M. Hermant, R. Hage, S. K. Mandal, V. G. Young, et al., Inorg. Chem. 1999, 38, 1929-1936.

A. J. Simaan, F. Banse, P. Mialane, A. Boussac, S. Un, T. Kargar-Grisel, G. Bouchoux, J. J. Girerd, Eur. J. Inorg. Chem. 1999, 993-996.

V. Balland, F. Banse, E. Anxolabéhère-Mallart, M. Ghiladi, T. A. Mattioli, C. Philouze, G. Blondin, J.-J. Girerd, Inorg. Chem. 2003, 42, 2470-2477.

A. Bondi, J. Phys. Chem. 1964, 68, 441-451. 
